\title{
Exploring implication of variation in biochar production on geotechnical properties of soil
}

Article

Accepted Version

Ganesan, S. P., Bordoloi, S., Ni, J., Sizmur, T., Garg, A. and Sekharan, S. (2020) Exploring implication of variation in biochar production on geotechnical properties of soil. Biomass Conversion and Biorefinery. ISSN 2190-6823 doi: https://doi.org/10.1007/s13399-020-00847-2 Available at https://centaur.reading.ac.uk/91810/

It is advisable to refer to the publisher's version if you intend to cite from the work. See Guidance on citing.

To link to this article DOI: http://dx.doi.org/10.1007/s13399-020-00847-2

Publisher: Springer

All outputs in CentAUR are protected by Intellectual Property Rights law, including copyright law. Copyright and IPR is retained by the creators or other copyright holders. Terms and conditions for use of this material are defined in the End User Agreement.

www.reading.ac.uk/centaur 
Central Archive at the University of Reading

Reading's research outputs online 
Exploring implication of variation in biochar production on geotechnical properties of soil

Suriya Prakash Ganesan, Sanandam Bordoloi, Junjun Ni*, Tom Sizmur, Ankit Garg*, Sreedeep Sekharan

Name: Suriya Prakash Ganesan

Title: Master's student

Affiliation: Institute of Civil Engineering, Qingdao University of Technology, China

Department of Civil and Environmental Engineering, Shantou University, China

Address: Institute of Civil Engineering, Qingdao University of Technology, China

E-mail: suriyaganesan1075@gmail.com

Name: Sanandam Bordoloi

Title: Post-Doctoral fellow

Affiliation: Department of Civil and Environmental Engineering, Hong Kong University of Science and Technology, China

Address: Department of Civil and Environmental Engineering, Hong Kong University of Science and Technology, China

E-mail: sanandam@ust.hk

\section{Name: Dr Junjun Ni* (Corresponding author)}

Title: Visiting Assistant Professor

Affiliation: Department of Civil and Environmental Engineering, Hong Kong University of Science and Technology, China

Address: Department of Civil and Environmental Engineering, Hong Kong University of Science and Technology, China

E-mail: cenijj@ust.hk

Name: Dr Tom Sizmur

Title: Associate Professor

Affiliation: Department of Geography and Environmental Science, University of Reading, United Kingdom

Address: Department of Geography and Environmental Science, University of Reading, United Kingdom E-mail: t.sizmur@ reading.ac.uk

Name: Dr Ankit Garg* (corresponding author)

Title: Associate Professor

Affiliation: Department of Civil and Environmental Engineering, Shantou University, China

Address: Department of Civil and Environmental Engineering, Shantou University, China

E-mail: ankit@stu.edu.cn

Name: Dr. Sreedeep S

Title: Professor

Affiliation: Department of Civil Engineering, Indian Institute of Technology Guwahati, India.

Address: Department of Civil Engineering, Indian Institute of Technology Guwahati, India

45 E-mail: srees@iitg.ac.in 
Abstract

51 Biochar produced from the pyrolysis of plant based feedstock has been advocated as an alternative

52 soil amendment for landfill cover. Previous literature indicated that the pyrolysis temperature

53 influences the intra-pore distribution and surface functional groups (especially hydroxyl groups),

54 resulting in "love-hate relationship" of the biochar amended soil (BAS) with water. From the

55 purview of geotechnical engineering, the effect of pyrolysis temperature on geotechnical

56 properties are rarely investigated. In total, three biochar rates $(0,5$ and $10 \%)$ were considered for

57 a set of geotechnical experiments in sand clay mixture soil with biochar produced at $350{ }^{\circ} \mathrm{C}$ and

$58550{ }^{\circ} \mathrm{C}$. Test results show that biochar addition in soil, in general regardless of pyrolysis

59 temperature, increased the optimum moisture content (OMC), plasticity index, soil water retention

60 characteristics (SWRC) and decreased the maximum dry density (MDD), shear strength

61 parameters (cohesion, friction), erosion rates. Whilst comparing the pyrolysis temperature effects

62 on two biochar amended soils, only marginal effects (in terms of magnitude) on SWRC were

63 observed. The most significant decrease of MDD (or increase of OMC) for 5\% (w/w) and 10\%

$64(\mathrm{w} / \mathrm{w})$ biochar additions occurred at pyrolysis temperatures of $550{ }^{\circ} \mathrm{C}$ and $350{ }^{\circ} \mathrm{C}$, respectively. In

65 addition, biochar produced at lower pyrolysis temperature $\left(350^{\circ} \mathrm{C}\right)$ was more effective in reducing

66 cracks and enhancing shrinkage area ratio. 10\% biochar addition with pyrolysis temperature of

$67350{ }^{\circ} \mathrm{C}$ was the optimum combination in resisting soil erosion. The study provides evidence that

68 the geotechnical properties of biochar amended soils for landfill cover soil applications could be

69 tailor made by controlling the pyrolysis temperature.

70 Keywords: cedar wood biochar, hydro-mechanical properties, landfill liner applications, pyrolysis 71 temperature

72

73 Notation

74 CW Cedar Wood

75 BAS Biochar Amended Soil

76 OMC Optimum Moisture Content

77 MDD Maximum Dry Density

78 CIF Crack Intensity Factor

79 SAR Shrinkage Area Ratio

80 SWRC Soil Water Retention Curve 


\section{Statement of Novelty}

83 In this paper, biochars (pyrolyzed from cedar wood feedstock) produced from two different 84 pyrolysis temperatures were amended with soil and examined for geotechnical properties in 85 landfill applications. The previous studies although reported the biochar material impact on soil 86 properties, the influence of pyrolysis temperature in the context of geotechnical assessment has

87 been rarely investigated. This study emphasizes the effect of pyrolysis temperature on various

88 geotechnical properties to better understand the effective utilization of biochar in landfill 89 applications

90

91

92

93

94

95

96

97

98

99

100

101

102

103

104

105

106

107

108

109 


\section{Introduction}

112 Bio-based soil amendment materials have gained traction in the past decade [1, 2]. Among these

113 bio-based amendments, biochar has been rediscovered as a sustainable soil amendment material

$114[3,4]$. Biochar is a carbonaceous porous material obtained from thermal degradation of plant-based

115 lignocellulose material under limited supply of oxygen and elevated temperatures termed as

116 pyrolysis $[\mathbf{5}, \mathbf{6}]$. The conversion of waste ligno-cellulose material into biochar helps in carbon

117 sequestration and has been extensively used in agricultural practices [7]. Recently, soil amended

118 with biochar was advocated as a promising final landfill cover material, as it suitably alters the

119 physical $[\mathbf{8 , 9}]$, hydraulic $[\mathbf{1 0}, \mathbf{1 1}]$, mechanical $[\mathbf{1 2}, \mathbf{1 3}]$ and biological $[\mathbf{1 4}]$ properties of the soil.

120 Biochar addition in soil was found to alter the physical properties such as porosity, saturated

121 hydraulic conductivity, surface area, crack potential and soil water retention characteristics

122 (SWRC) [15-17]. Those changes in soil physical properties may promote the growth of vegetation,

123 which affects the soil hydrological responses and stability of earthen infrastructures [18-21]. The

124 soil mechanical properties such as shear strength, erosion potential and liquefaction potential were 125 also reported to be altered by biochar $[\mathbf{2 2}, \mathbf{2 3}]$. These variations in geotechnical properties for

126 biochar amended soil (BAS) is majorly attributed to biochar gradation, intra-pores of biochar and 127 surface functional groups.

From the purview of geotechnical engineering, the production conditions (e.g. pyrolysis

129 temperature) and its consequent effect on geotechnical properties has rarely been investigated. It

130 is important to understand these relationships because the pyrolysis temperature plays a pivotal

131 role in determining the biochar particle size, its inherent intra-pore distribution and surface

132 functional groups (whether hydrophilic or hydrophobic) [24]. From a material science perspective,

133 the effect of pyrolysis temperatures and feedstock types on chemical, morphological and physical

134 characteristics has been well documented [25-27]. Studies clearly indicated that the feedstock

135 types affect the biochar yield, elemental compositions and other soil properties such as porosity 136 and bulk density [28]. This is due to variation in cellulose, hemicellulose and lignin for different 137 plant-based biomass [29]. In addition, the "love hate relationship" of soil-biochar composite and 138 water is influenced by the variations of surface functional groups and morphology at different 139 pyrolysis temperatures. In biochar, where a broad spectrum of hydroxyl group (-OH) found at the 140 surface of the biochar, determines the hydrophilic nature of the biochar. Previous studies reported 
141 that the hydrophilic nature of the biochar increases its affinity towards water [30, 31]. In the 142 contrary, the biochar produced at higher temperature can increase the number of intrapores

143 (mesopores). The increased intrapores have the ability to store water but possess less affinity 144 towards water due to the hydrophobic nature of the biochar (less pronounced hydroxyl band). As 145 functional groups and biochar intra-pores influence the granular arrangement, water retention and 146 strength characteristics of BAS, it is imperative that the geotechnical properties of the composite 147 with biochar produced at different temperatures need to be explored. This exploration will help 148 geotechnical practitioners have a better understanding on the use of biochar which might pave way 149 to a new direction for classification system for biochar, as is the case for fly ash [32].

150 The overarching aim of this work is to provide an elementary understanding of the 151 influence of pyrolysis temperature on the geotechnical properties of BAS. Cedar wood biochar 152 obtained after in-house pyrolysis at $350{ }^{\circ} \mathrm{C}$ and $550{ }^{\circ} \mathrm{C}$ was mixed with a silty sand soil at $0 \%, 5 \%$ 153 and $10 \%(\mathrm{w} / \mathrm{w})$. The composites prepared were measured for their compaction characteristics, 154 Atterberg limits, shrinkage and crack area ratio, shear strength, erosion potential and SWRC. The 155 microstructure of biochar and surface functional groups were analyzed beforehand to facilitate the 156 interpretation of these measured parameters.

\section{Materials and Methods}

\section{Soil and biochar characteristics}

161 An un-amended bare soil and four cedar wood biochar amended soil designated as CW-T-BP (refer 162 Table 1), were analyzed in the current study. The soil was classified as sand clay mixture (SC) 163 according to Unified Soil Classification System [33]. The soil consists of 50\% sand (coarse sand$16419 \%$, medium sand-16\% and fine sand-16\%), 19\% silt and 30\% clay particles. The Atterberg 165 limits, compaction characteristics and specific gravity are tabulated in Table 2 . This type of soil 166 has been extensively used as a cover material in landfill liner in countries, such as India, Hong 167 Kong and United States [34-37].

168 The produced biochars were tested for the surface functional groups and significant 169 changes of hydrophilic groups were observed in the biochars pyrolyzed at $350{ }^{\circ} \mathrm{C}(\mathrm{CW}-350)$ and $170550{ }^{\circ} \mathrm{C}(\mathrm{CW}-550) . \mathrm{CW}-350$ contained un-pyrolyzed hydrophilic surfaces and functional groups, 
171 while CW-550 was fully pyrolyzed and aromatic in nature. These two biochars were selected for

172 further investigation and, since they were broadly representative of low temperature (incomplete)

173 pyrolysis and high temperature (complete) pyrolysis as reported in literature for the selected

174 feedstock [38]. The chemical properties of feedstock and the corresponding biochars are presented

175 summarized in Table 3.

176 Surface properties of biochar

177 The morphology of the two produced biochars were analyzed using Field Emission Scanning 178 Electron Microscopy (FE-SEM). Figure 1 clearly showcased the contrasting morphology of the 179 two biochars wherein a high density of intra-pores is observed in case of CW-550. This observation 180 is expected due to the thermal degradation of relatively simple biopolymers (cellulose and 181 hemicellulose), which degrades faster than complex lignin biopolymers [15, 39]. At both 182 magnifications (200X and 1000X), CW-550 reveals a honeycomb intra-pore structure on the 183 entirety of its surface, which was not seen at CW-350. This honeycomb structure is expected as 184 lignin engulfs the cellulose and hemicellulose biopolymers in a similar structural arrangement [40]. 185 Figure 2 helps us to understand the surface functional groups of the two produced biochars by 186 analyzing the infrared spectrum of absorption using Fourier Transformation Infra-Red (FTIR) 187 spectroscopy. It is clearly visible that the major hydrophilic functional group i.e. hydroxyl 188 disappears at CW-550 indicated by the apparent reduction of peaks at wavelengths near $3500 \mathrm{~cm}^{-}$

$189^{1}$ (Fig. 2). In general, the peaks for most of the functional groups are less pronounced for CW-350, 190 compared to CW-550, indicating that the water holding capacity of the biochar would be reduced 191 with higher pyrolysis temperatures.

\section{Experimental setup and procedure}

193 The shrinkage area ratio (SAR) and crack intensity factor (CIF), which gives an indication of the 194 shrinkage and desiccation potential of soil was measured using image analysis $[\mathbf{3 6}, \mathbf{4 1}, \mathbf{4 2}]$. For 195 CIF and SAR experiments, all the soil samples were prepared at liquid limit state in a cylindrical 196 mould (20 cm in diameter) and the samples were allowed to dry naturally at room temperature. At 197 regular interval of 60 minutes, images of the surface area and the corresponding water content in 198 the soil have been monitored. The CIF and SAR values were calculated from the image analysis 199 of the obtained pictures. 
For erosion assessment, the BAS samples are statically compacted within the mold having 201 the dimensions of $2.5 \mathrm{~cm}$ diameter and $5 \mathrm{~cm}$ length, respectively. A $7 \mathrm{~mm}$ diameter opening is 202 drilled at the center of the sample along the axis. The size of the hole was based on the 203 consideration that the higher flow rates require a bigger hole to initiate erosion and a small hole 204 may cause significant re-deposition of eroded particles on its walls [43]. Drilled samples were 205 installed in pinhole setup and was subjected to different increasing continuous flowrates. The 206 eroded particles were collected by passing the eroded effluent through Whatman filter paper (Fig. 207 5e). The eroded mass was estimated by oven drying method. The shear stress and erosion rate for 208 a specific flow rate was estimated. The corresponding critical shear stress and erodibility 209 coefficient were estimated for every soil state as done previously by Kumar et al. [23]

210 The shear strength parameters such as cohesion and friction angle were measured using the 211 direct shear apparatus. The soil samples were prepared in a shear box of dimension $60 \mathrm{~mm} * 60$ $212 \mathrm{~mm} * 50 \mathrm{~mm}$ at maximum density obtained from the compaction characteristics. The instrument 213 provides the shear stress value for the applied normal stress. The shear strength parameters of 214 cohesion and friction angle were obtained from the shear stress vs normal stress plots. The soil 215 water retention curve was measured using WP4C dew point potentiometer, which gives the 216 indirect measurement of soil suction using the kelvin equation considering the humidity of the air 217 above soil sample [44]. The gravimetric water content of the soil sample is measured followed by 218 the suction measurement. The soil samples were prepared at maximum dry density state. All the 219 experiments were repeated three times at a minimum in order to minimize errors and ascertain the 220 variability.

\section{Results and Discussion}

\section{Index properties and compaction state of biochar amended soil}

224 The Atterberg limits (liquid limit, plastic limit and shrinkage limit) for bare soil and BAS are

225 reported in Table 2. There is a significant increase in the liquid limit and plastic limit for BAS at 226 both temperatures $\left(350^{\circ} \mathrm{C}\right.$ and $\left.550{ }^{\circ} \mathrm{C}\right)$. This observation is attributed to the higher intra pore 227 spaces (Fig. 1) which facilitate more water to be stored in the soil voids as well as in the intra-pore 228 voids [23]. The plasticity index was also sensitive to the addition of biochar, and was increased at 229 higher application rates and at higher pyrolysis temperatures. Figure $\mathbf{3}$ shows the compaction 
curves for bare soil and BAS. The maximum dry density and corresponding optimum moisture

231 content (OMC) for the bare soil were $17 \mathrm{kN} / \mathrm{m}^{3}$ and $17.2 \%$, respectively. It was seen that after

232 addition of biochar, the dry density decreased to $15.5-13.1 \mathrm{kN} / \mathrm{m}^{3}$, while the OMC increased to

$23319.1 \%-25.2 \%$, depending on the amendment rate and pyrolysis temperature. In 5\% biochar

234 addition, the magnitude of MDD decrease and OMC increase was higher at CW-550. This can be

235 explained by very finer particle size of the biochar obtained at $550{ }^{\circ} \mathrm{C}$ pyrolysis temperature than

236 that at $3500 \mathrm{C}$. The finer biochar particles at CW-550 increases the specific surface areas [45] and

237 reduces the specific gravity of the composite to a greater extent than those at CW-350. Hence the

238 MDD value decreased and OMC increased significantly at CW-550 for 5\% biochar amendment

239 rate. However, for $10 \%$ biochar addition, the characteristics are reversed, such that the magnitude

240 of MDD decrease and OMC increase was higher at CW-350. Since the amendment rate is high,

241 the finer particles of biochar at CW-550 tightly clogged soil voids during compaction. This

242 mechanism can be substantiated by the surface morphology images portrayed in Fig. 1 and

243 previous report by [45]. The tightly packed soil-biochar composite with pore clogging is

244 implausible at CW-350 due to quite coarser nature of biochar obtained at $350{ }^{\circ} \mathrm{C}$ pyrolysis

245 temperature. Therefore, MDD decrease and OMC increase was found to be higher at CW-350.

246 Based on the above discussion, it can be concluded that biochar particle size has greater influence

247 on compaction characteristics for smaller biochar amendment rate (e.g., 5\%). However, for higher

248 amendment rate (e.g., 10\%), the compaction characteristics are mainly dominated by pore clogging

249 of fine particles in the composite.

\section{Shrinkage and desiccation potential of biochar amended soil}

251 Figure 4 shows the CIF and SAR variation at different water content for bare soil and BAS. CIF

252 is the ratio of the cracked area at the soil surface to the total area of the soil specimen $[\mathbf{4 2}, \mathbf{4 6}]$. As

253 water content decreases, the CIF increases from zero up to a certain value and then levels off

254 indicating peak CIF $[36,47]$. The peak CIF decreases with respect to bare soil by almost $73 \%$ for

255 both CW-350-5\% and CW-350-10\%. For CW-550-5\% and CW-550-10\%, the peak CIF decreases

256 up to $56 \%$ and $66 \%$, respectively. At CW-350, as the hydroxyl groups are abundant (seen in the

257 FTIR spectra) and the water present in the resulting BAS naturally results in less cracks. On the

258 other hand, the lesser abundance of hydroxyl groups on the surface of CW-550 means that it retains

259 less water and thus has a higher CIF at both amendment rates compared to CW-350. The SAR

260 indicates the ratio of shrinked area to the initial cross-sectional area of soil [48] The BS shrinks to 
74\% of original area whereas CW-350-5\% and CW-350-10\% shrinks to $86 \%$ to $89 \%$ of original 262 area relatively at the end of drying. The CW-550-5\% and CW-550-10\% shrinks up to $75 \%$ to $79 \%$ 263 of original area, thus showing that CW-350 has better shrinkage mitigation overall (similar to CIF 264 response).

\section{Shear strength and erodibility parameters of biochar amended soil}

266 Figure 5 presents the shear stress versus normal stress response for all soil samples and their respective shear parameters (cohesion (c) and angle of friction $(\phi)$ ). It can be seen that cohesion of BAS decreases with respect to bare soil. The $\phi$ increases with addition of biochar for both BAS prepared at $350^{\circ} \mathrm{C}$ and $550^{\circ} \mathrm{C}$. In the context of amendment rates, for the BAS, the composite prepared at $550{ }^{\circ} \mathrm{C}$ showed less cohesion with respect to $350^{\circ} \mathrm{C}$ which can be explained by the absence of hydrophilic (-OH) groups. At $350^{\circ} \mathrm{C}$, with an increase in biochar amendment rate, the cohesion increases due to more abundant $(-\mathrm{OH})$ groups. The same is not observed for BAS with $\mathrm{CW}-550$ since cohesion is lower at the higher application rates. At biochar amendment rate 10\%, CW-550 has a higher percentage of finer particles that CW-350. The increased fine particles can reduce the contact friction between coarse grains and hence decrease the shear resistance [49]. That is why at lower normal stress $(50 \mathrm{kPa}), \mathrm{CW}-550$ has much lower shear strength than $\mathrm{CW}$ 350 . However, with the increase of normal stress to $150 \mathrm{kPa}$, stress-induced particle rearrangement and clogging of soil pores by finer biochar particles become more significant in CW-550 (Fig. 1). The increase of pore clogging and hence soil density under higher stress in CW-550 causes the interlocking between particles and hence the tendency to soil dilatancy [50], resulting in a higher shear strength.

Figure 6 shows the variation of erosion rate with shear stress for bare soil and BAS for three different compaction states (i.e. OMC-5\%, OMC and OMC+5\%). It was seen that an increase in moisture resulted in decrease in erosion rate for both BS and BAS, which is attributed to apparent cohesive force between soil particles in the presence of water [51] and the particle orientation change from flocculated to dispersed [52]. Runoff water can easily erode the

287 flocculated particles in dry side, as there is edge-to-face interaction. On the other hand, flow 288 happens along the particle surface in dispersed orientation (wet side) producing relatively less drag 289 [53]. The effect of different pyrolysis temperature was evident in the erosion response for BAS 290 constituted by hydrophilic CW-350-5\% and CW-350-10\%, showing lower erosion with respect to 
291 CW-550-5\% and CW-550-10\%, at all compaction states. Furthermore, the erosion rate decreases

292 with increased amendment rates for both CW-350 and CW-550.

\section{Soil water retention of biochar amended soil}

294 Figure 7 presents the soil water retention response of bare soil and BAS. It was observed that 295 inclusion of both CW-350 and CW-550 in soil increased the water retention capacity of the soil. 296 Regardless of the biochar amendment rate and pyrolysis temperature, all BAS gave a similar SWR 297 response. This response of BAS was also observed by Wong et al. [54] for compacted Kaolinite 298 soil (at 0.9 degree of compaction) amended with peanut-shell biochar (Fig. 7). Thus, it can be 299 inferred that at high suction (beyond $1000 \mathrm{kPa}$ ), the effect of different functional groups and intra300 pore volume of biochar does not significantly affect the SWR.

\section{Conclusions}

303 This study explored the effects of biochar pyrolyzed at $350{ }^{\circ} \mathrm{C}$ and $550{ }^{\circ} \mathrm{C}$ applied to a silty sand at $3045 \%$ and $10 \%(\mathrm{w} / \mathrm{w})$ on the geotechnical properties of the amended soil. The microstructure of 305 produced biochar and its surface functional groups revealed that the intra-pores increase, and 306 surface functional group were lower for biochar produced at higher temperature. There is 307 contrasting hydrophobic and hydrophilic characteristics of biochar as pyrolysis temperature 308 increases, due to decrease in -OH groups and higher intra-pore volume, respectively. The pyrolysis 309 temperature played a major role by altering the basic compaction characteristics (increase in OMC 310 and decrease in dry density due to its porous nature) as reported in previous studies. Whilst 311 analyzing the major objective, biochar pyrolyzed at lower temperature (CW-350) mitigates better

312 in cracking and shrinkage potential than the higher temperature residues (CW-550). This is mainly 313 due to the hydrophilic nature of CW-350, which helps at retaining water in the soil-biochar matrix. 314 However, the same advantage contradicts the shear strength properties with decrease in cohesion 315 irrespective of the amendment rates. On the other hand, the soil water retention curves also shows 316 better response when compared with the bare soil, due to the obvious water retention in the 317 intrapores of the biochar. Thus, the biochar produced at lower temperatures might act better in the 318 landfill applications after plant establishment (for strength increase) of the cover surface 319 considering the aspects of energy reduction and cost intensiveness. Besides, the adverse effects of 
320 pyrolysis temperature with biochar obtained from different feedstocks and the effect of pyrolysis 321 temperature on leaching potential of BAS should be studied in future.

\section{Acknowledgments}

324 The authors would like to acknowledge Shantou University Scientific Research Fund (NTF17007) 325 for the support.

\section{References}

1. Liang S, Han Y, Wei L, McDonald AG (2014) Production and characterization of bio-oil and bio-char from pyrolysis of potato peel wastes. Biomass Conv Bioref 5:237-246. https://doi.org/10.1007/s13399-014-0130-X

2. Machineni L (2019) Lignocellulosic biofuel production: review of alternatives. Biomass Conv Bioref. https://doi.org/10.1007/s13399-019-00445-X

3. Shalini SS, Palanivelu K, Ramachandran A, Raghavan V (2020) Biochar from biomass waste as a renewable carbon material for climate change mitigation in reducing greenhouse gas emissions - a review. Biomass Conv Bioref https://doi.org/10.1007/s13399-02000604-5

4. Singh R, Srivastava P, Singh P, Sharma AK, Singh H, Raghubanshi AS (2019) Impact of rice-husk ash on the soil biophysical and agronomic parameters of wheat crop under a dry tropical ecosystem. Ecol Indic 105:505-515. https://doi.org/10.1016/j.ecolind.2018.04.043

5. Liu R, Liu G, Yousaf B, Abbas Q (2018) Operating conditions-induced changes in product yield and characteristics during thermal-conversion of peanut shell to biochar in relation to economic analysis. J Clean Prod 193:479-490. https://doi.org/10.1016/j.jclepro. $\underline{2018.05 .034}$

6. Yang S, Li B, Zheng J, Kankala RK (2018) Biomass-to-Methanol by dual-stage entrained flow gasification: Design and techno-economic analysis based on system modeling. J Clean Prod 205:364-374. https://doi.org/10.1016/j.jclepro.2018.09.043 
7. Jeffery S, Verheijen FG, Van der Velde M, Bastos AC (2011) A quantitative review of the effects of biochar application to soils on crop productivity using meta-analysis. Agr Ecosyst Environ 144(1):175-187. https://doi.org/10.1016/j.agee.2011.08.015

8. Ulyett J, Sakrabani R, Kibblewhite M, Hann M (2014) Impact of biochar addition on water retention, nitrification and carbon dioxide evolution from two sandy loam soils. Eur J Soil Sci 65(1):96-104. https://doi.org/10.1111/ejss.12081

9. Abel S, Peters A, Trinks S, Schonsky H, Facklam M, Wessolek G (2013) Impact of biochar and hydrochar addition on water retention and water repellency of sandy soil. Geoderma 202:183-191. https://doi.org/10.1016/j.geoderma.2013.03.003

10. Wong JTF, Chen Z, Chen X, Ng CWW, Wong MH (2017) Soil-water retention behavior of compacted biochar-amended clay: a novel landfill final cover material. J Soil Sediment 17(3):590-598. https://doi.org/10.1007/s11368-016-1401-x

11. Yaghoubi P, Reddy KR (2011) Characteristics of biochar-amended soil cover for landfill gas mitigation. In Pan-Am CGS Geotechnical Conference.

12. Chen XW, Wong JTF, Ng CWW, Wong MH (2016) Feasibility of biochar application on a landfill final cover-a review on balancing ecology and shallow slope stability. Environ Sci Pollut Res 23(8):7111-7125. https://doi.org/10.1007/s11356-015-5520-5

13. Das O, Sarmah AK, Bhattacharyya D (2016) Bio composites from waste derived biochars: mechanical, thermal, chemical, and morphological properties. Waste Manag 49:560-570. https://doi.org/10.1016/j.wasman.2015.12.007

14. Swagathnath G, Rangabhashiyam S, Murugan S, Balasubramanian P (2019) Influence of biochar application on growth of Oryza sativa and its associated soil microbial ecology. Biomass Convers Bioref 9:341-352. https://doi.org/10.1007/s13399-018-0365-z

15. Pardo GS, Sarmah AK, Orense RP (2018) Mechanism of improvement of biochar on shear strength and liquefaction resistance of sand. Geotechnique 69(6):471-480. https://doi.org/10.1680/jgeot.17.P.040

16. Ni JJ, Chen XW, Ng CWW, Guo HW (2018) Effects of biochar on water retention and matric suction of vegetated soil. Geotech Lett 8(2):124-129. https://doi.org/ $\underline{10.1680 / \text { jgele. } 17.00180}$ 
17. Ni JJ, Bordoloi S, Shao W, Garg A, Xu G, Sarmah AK (2020) Two-year evaluation of hydraulic properties of biochar-amended vegetated soil for application in landfill cover system. Sci Total Environ 712:136486. https://doi.org/10.1016/j.scitotenv.2019.136486

18. Ng CWW, Ni JJ, Leung AK (2019a) Effects of plant growth and spacing on soil hydrological changes: A field study. Géotechnique. https://doi.org/10.1680/ jgeot.18.P.207

19. Ng CWW, Ni JJ, Leung AK (2019b) Plant-Soil Slope Interaction. Taylor \& Francis. ISBN 978-1-138-19755-8. 8. 206p. 1st Edition: 2 Aug 2019.

20. Ni JJ, Leung AK, Ng CWW (2019a) Modelling effects of root growth and decay on soil water retention and permeability. Can Geotech J 56(7): 1049-1055. https://doi.org/ $\underline{10.1139 / \mathrm{cgj}-2018-0402}$

21. Ni JJ, Leung AK, \& Ng CWW (2019b) Unsaturated hydraulic properties of vegetated soil under single and mixed planting conditions. Géotechnique 69(6): 554-559. https://doi.org/ 10.1680/jgeot.17.T.044

22. Reddy KR, Yaghoubi P, Yukselen-Aksoy Y (2015) Effects of biochar amendment on geotechnical properties of landfill cover soil. Waste Manag. Res 33(6):524-532. $\underline{10.1177 / 0734242 X 15580192}$

23. Kumar H, Ganesan SP, Bordoloi S, Sreedeep S, Lin P, Mei G, Garg A, Sarmah AK (2019) Erodibility assessment of compacted biochar amended soil for geo-environmental applications. Sci Total Environ 672:698-707. https://doi.org/10.1016/j.scitotenv. $\underline{2019.03 .417}$

24. Liu Z, Dugan B, Masiello CA, Gonnermann HM (2017) Biochar particle size, shape, and porosity act together to influence soil water properties. PloS One 12(6):e0179079. https://doi.org/10.1371/journal.pone.0179079

25. Angin D, Şensoz S (2014) Effect of pyrolysis temperature on chemical and surface properties of biochar of rapeseed (Brassica napus L.). Int J Phytoremediat 16(7-8):684693. https://doi.org/10.1080/15226514.2013.856842

26. Sun Y, Gao B, Yao Y, Fang J, Zhang M, Zhou Y, Chen H, Yang L (2014) Effects of feedstock type, production method, and pyrolysis temperature on biochar and hydrochar properties. Chem Eng J 240:574-578. https://doi.org/10.1016/j.cej.2013.10.081 
27. Guizani C, Jeguirim M, Valin S, Limousy L, Salvador S (2017) Biomass chars: The effects of pyrolysis conditions on their morphology, structure, chemical properties and reactivity. Energies 10(6):796. https://doi.org/10.3390/en10060796

28. Alburquerque JA, Calero JM, Barrón V, Torrent J, Campillo MC, Gallardo A, Villar R (2014) Effects of biochars produced from different feedstocks on soil properties and sunflower growth. J Plant Nutr Soil Sci 177(1):16-25. https://doi.org/10.1002/ jpln.201200652

29. Bordoloi S, Garg A, Sekharan S (2017) A review of physio-biochemical properties of natural fibers and their application in soil reinforcement. Adv Civ Eng Mater 6(1):323-359. https://doi.org/10.1520/ACEM20160076

30. Das O, Sarmah AK (2015) The love-hate relationship of pyrolysis biochar and water: a perspective. Sci Total Environ 512:682-685. https://doi.org/10.1016/j.scitotenv. $\underline{2015.01 .061}$

31. Gray M, Johnson MG, Dragila MI, Kleber M (2014) Water uptake in biochar: The roles of porosity and hydrophobicity. Biomass Bioenerg 61:196-205. https://doi.org/10.1016/ j.biombioe.2013.12.010

32. Roy WR, Thiery RG, Schuller RM, Suloway JJ (1981) Coal fly ash: a review of the literature and proposed classification system with emphasis on environmental impacts. Environ Geol 96.

33. ASTM D2487 (2017) Standard Practice for Classification of Soils for Engineering Purpose (Unified Soil Classification System). ASTM International, West Conshohocken, PA.

34. Sadasivam BY, Reddy KR (2015) Adsorption and transport of methane in landfill cover soil amended with waste-wood biochars. J Environ Manag 158:11-23. https://doi.org/10.1016/j.jenvman.2015.04.032

35. Ng CWW, Chen R, Coo JL, Jian L, Ni JJ, Chen Y, Zhan L, Guo H, Bangwen L (2018) A novel vegetated three-layer landfill cover system using recycled construction wastes without geomembrane. Can Geotech J 56(12):1863-1875. https://doi.org/10.1139/cgj$\underline{2017-0728}$

36. Bordoloi S, Garg A, Sreedeep S, Lin P, Mei G (2018) Investigation of cracking and water availability of soil-biochar composite synthesized from invasive weed water hyacinth. Bioresour Technol 263:665-677. https://doi.org/10.1016/j.biortech.2018.05.011 
37. Sheikh J, Bordoloi S, Yamsani S, Sreedeep S, Rakesh RR, Sarmah AK (2019) Long-term hydraulic performance of landfill cover system in extreme humid region: Field monitoring and numerical approach. Sci Total Environ 688:409-423. https://doi.org/10.1016/ j.scitotenv.2019.06.213

38. Rodríguez-Vila A, Selwyn-Smith H, Enunwa L, Smail I, Covelo EF, Sizmur T (2018) Predicting $\mathrm{Cu}$ and $\mathrm{Zn}$ sorption capacity of biochar from feedstock $\mathrm{C} / \mathrm{N}$ ratio and pyrolysis temperature. Environ Sci Pollut Res 25(8):7730-7739. 10.1007/s11356-017-1047-2

39. Lehmann J, Joseph S (2015) Biochar for environmental management: science, technology and implementation. Routledge.

40. Bordoloi S, Gopal P, Boddu R, Wang Q, Cheng YF, Garg A, Sreedeep S (2019) Soilbiochar-water interactions: role of biochar from Eichhornia crassipes in influencing crack propagation and suction in unsaturated soils. J Clean Prod 210:847-859. https://doi.org/10.1016/j.jclepro.2018.11.051

41. Rasband WS (2011) ImageJ. US National Institutes of Health, Bethesda, Maryland, USA.

42. Yesiller N, Miller, CJ, Inci G, Yaldo K (2000) Desiccation and cracking behavior of three compacted landfill liner soils. Eng Geol 57(1-2):105-121. https://doi.org/10.1016/S0013$\underline{7952(00) 00022-3}$

43. Reddi LN, In-Mo L, Bonala MVS (2000) Comparison of Internal and Surface Erosion Using Flow Pump Tests on a Sand-Kaolinite Mixture. Geotech Test J 23(1):116-122. https://doi.org/10.1520/GTJ11129J

44. Simms P, Soleimani S, Mizani S, Daliri F, Dunmola A, Rozina E, Innocent-Bernard T (2017) Cracking, salinity and evaporation in mesoscale experiments on three types of tailings. Environ Geotech 6(1):3-17. https://doi.org/10.1680/jenge.16.00026

45. Liu Z, Dugan B, Masiello CA, Barnes RT, Gallagher ME, Gonnermann H (2016) Impacts of biochar concentration and particle size on hydraulic conductivity and DOC leaching of biochar-sand mixtures. J Hydrol 533: 461-472. https://doi.org/10.1016/ j.jhydrol.2015.12.007

46. Liu Z, Dugan B, Masiello CA, Gonnermann HM (2017) Biochar particle size, shape, and porosity act together to influence soil water properties. Plos one 12(6): e0179079. https://doi.org/10.1371/journal.pone.0179079 
47. Li JH, Li L, Chen T, Li DQ (2016) Cracking and vertical preferential flow through landfill clay liners. Eng Geol 206:33-41. https://doi.org/10.1016/j.enggeo.2016.03.006

48. Wan Y, Wu C, Xue Q, Hui X (2019) Effects of plastic contamination on water evaporation and desiccation cracking in soil. Sci Total Environ 654:576-582. https://doi.org/10.1016/j.scitotenv.2018.11.123

49. Carraro JAH, Prezzi M, Salgado R. (2009) Shear strength and stiffness of sands containing plastic or non-plastic fines. J Geotech Geoenviron 135(9): 1167-1178. https://doi.org/10.1061/(ASCE)1090-0241(2009)135:9(1167)

50. Bolton MD (1986) The strength and dilatancy of sands. Geotechnique 36(1): 65-78. https://doi.org/10.1680/geot.1986.36.1.65

51. Chepil WS (1956) Influence of Moisture on Erodibility of Soil by Wind 1. Soil Sci Soc Am J 20(2):288-292. https://doi.org/10.2136/sssaj1956.03615995002000020033x

52. Lambe TW (1958) The structure of compacted clay. J Soil Mech Found Div 84(2):1-34

53. Grissinger EH (1966) Resistance of selected clay systems to erosion by water. Water Resour Res 2(1):131-138. https://doi.org/10.1029/WR002i001p00131

54. Wong JTF, Chen Z, Wong AYY, Ng CWW, Wong MH (2018) Effects of biochar on hydraulic conductivity of compacted kaolin clay. Environ Pollut 234:468-472. https://doi.org/10.1016/j.envpol.2017.11.079

55. ASTM D422-63 (2007) Standard Test Method for Particle-size Analysis of Soils. ASTM International, West Conshohocken, PA.

56. ASTM D4318 (2010) Standard Test Methods for Liquid Limit, Plastic Limit and Plasticity Index of Soils. ASTM International, West Conshohocken, PA.

57. ASTM D1557 (2012) Standard test methods for laboratory compaction characteristics of soil using modified effort. ASTM International, West Conshohocken, PA. Pycnometer. ASTM International, West Conshohocken, PA.

59. ASTM D3080 (2011) Standard test method for direct shear test of soils under consolidated drained conditions. ASTM International, West Conshohocken, PA. 


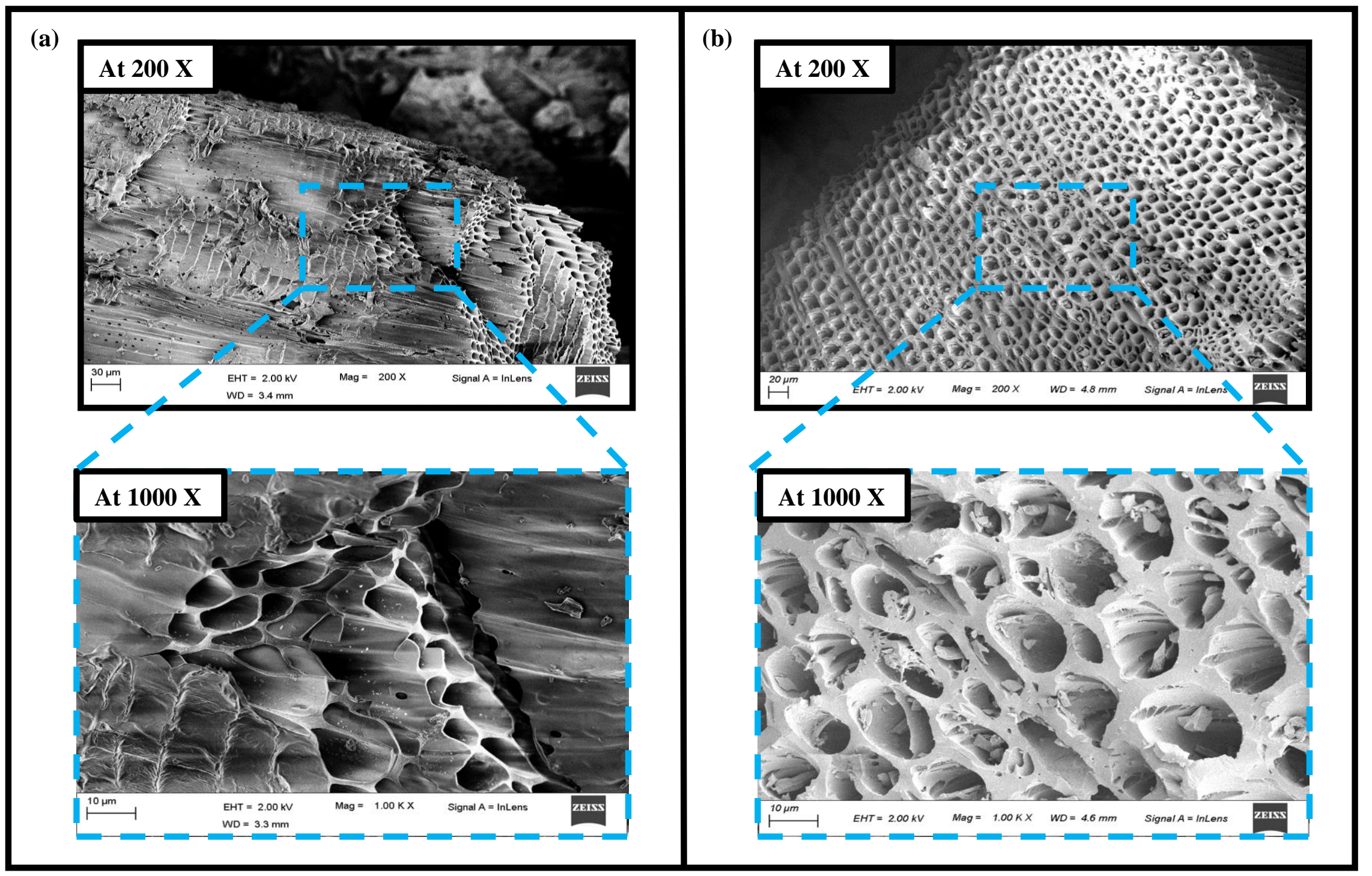

Fig. 1 Surface morphology of cedar wood biochar depicted with FE-SEM images a) $350{ }^{\circ} \mathrm{C}$; b) $550{ }^{\circ} \mathrm{C}$ 


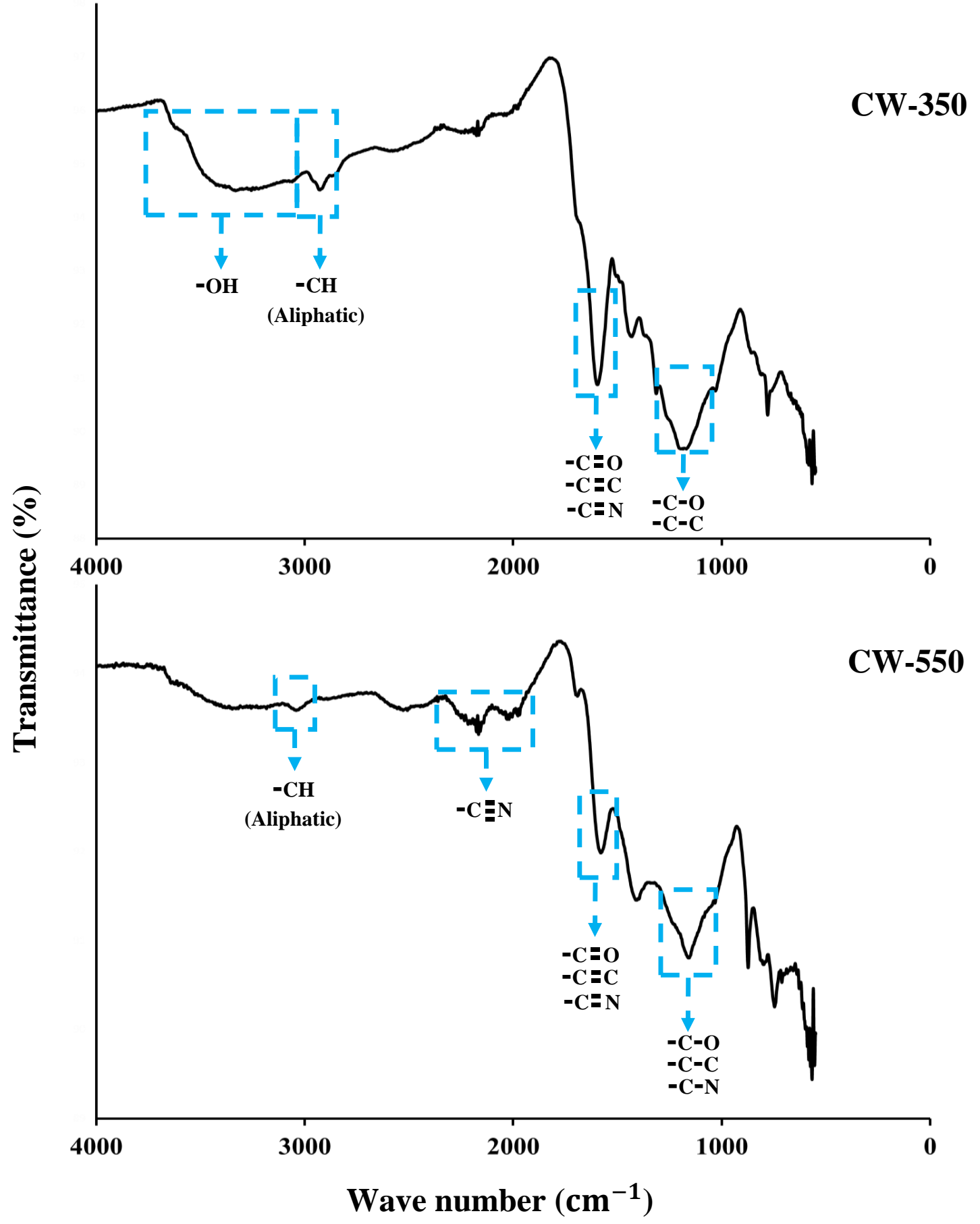

Fig. 2 FTIR results depicting the functional groups of cedar wood biochar at $350{ }^{\circ} \mathrm{C}$ and $550{ }^{\circ} \mathrm{C}$ 


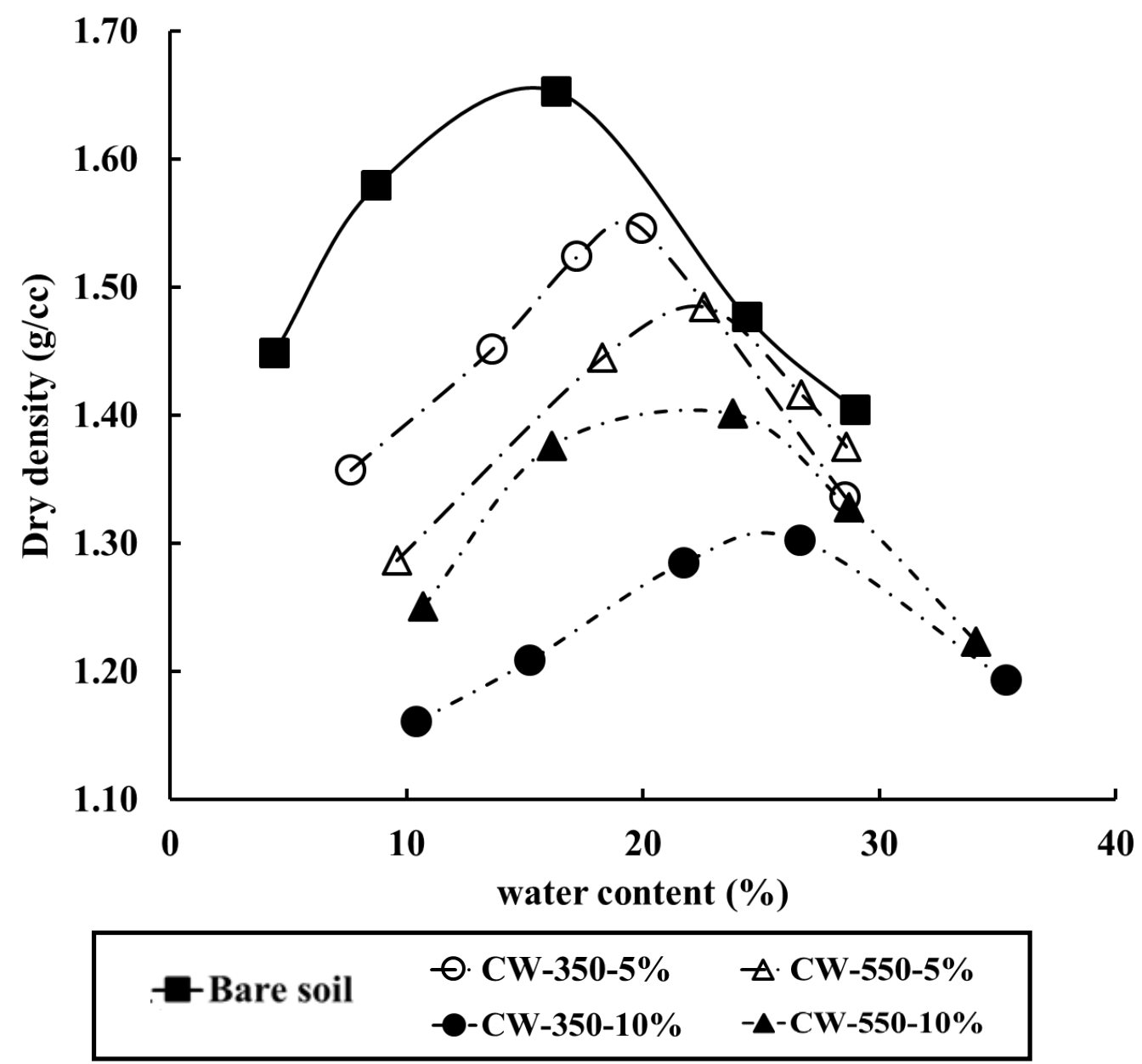

Fig. 3 Compaction curves for bare soil and cedar wood biochar amended soils at 5\% and 10\% 


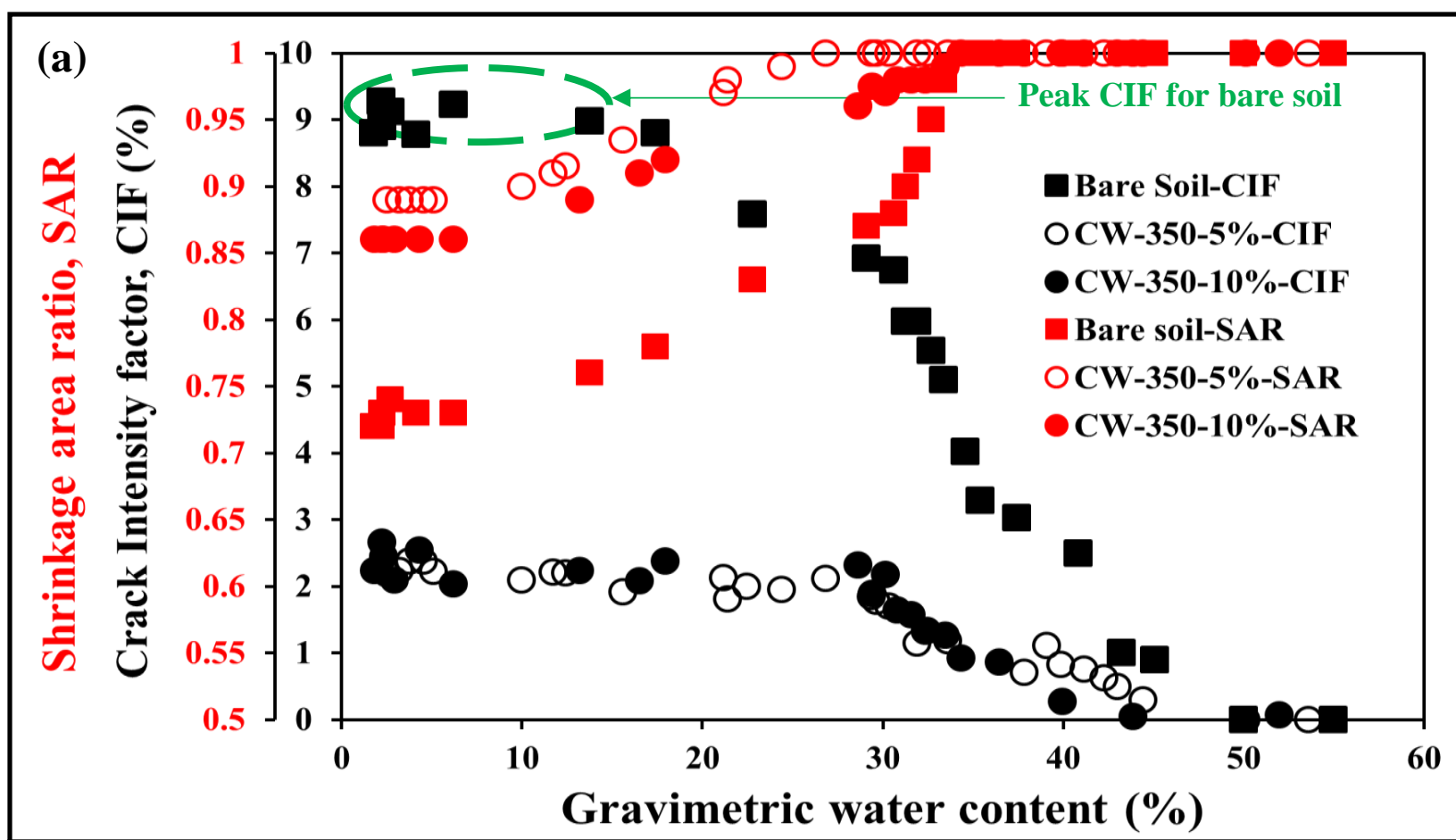

(b)

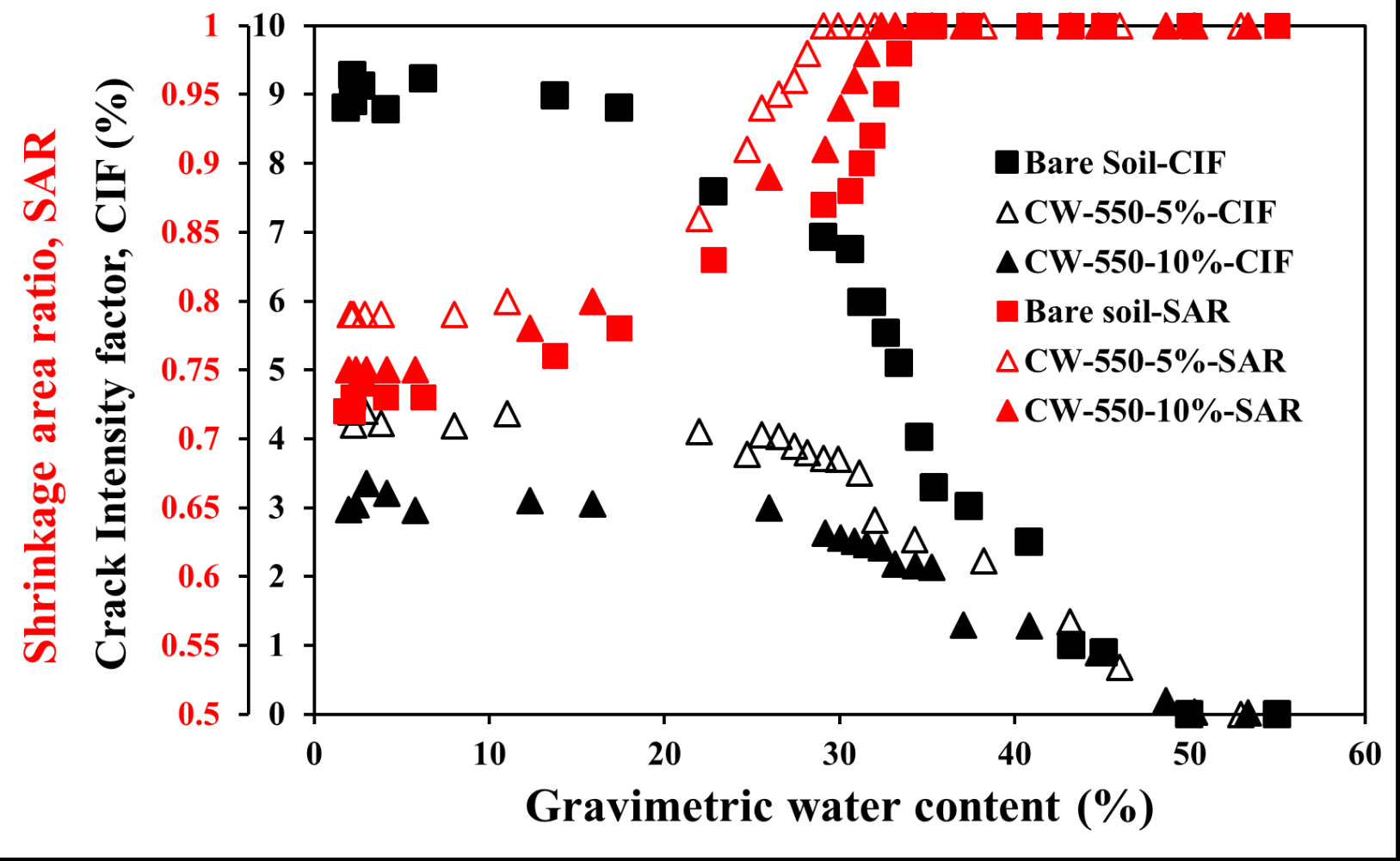

Fig. 4 SAR and CIF variation with moisture content for bare soil and soil-biochar composite produced at (a) $350{ }^{0} \mathrm{C}$ and (b) $550{ }^{\circ} \mathrm{C}$. 


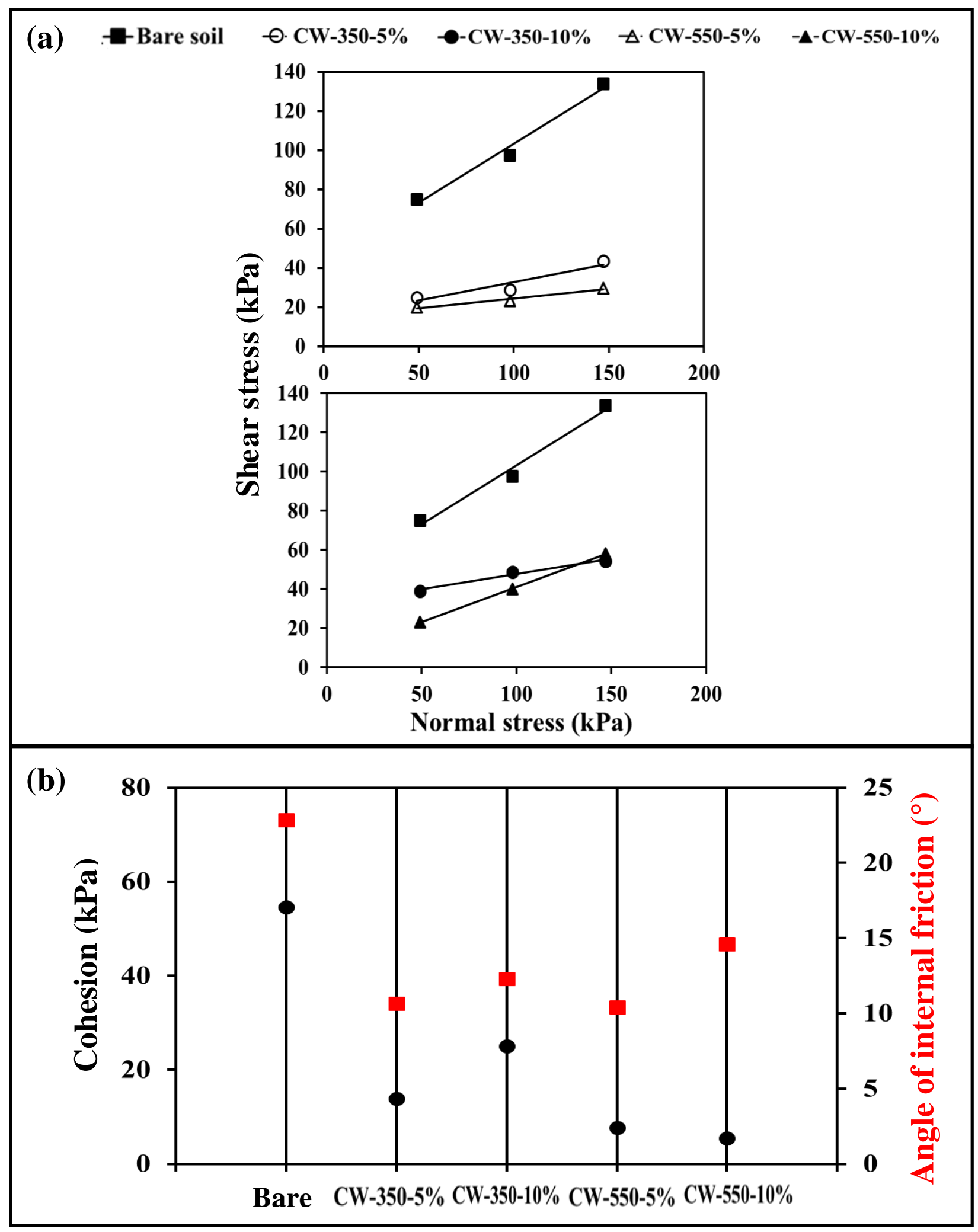

Fig. 5 Direct shear test response for bare soil and biochar amended soil represented as (a) shear stress vs normal stress (b) cohesion and angle of internal friction 


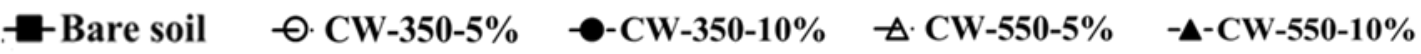
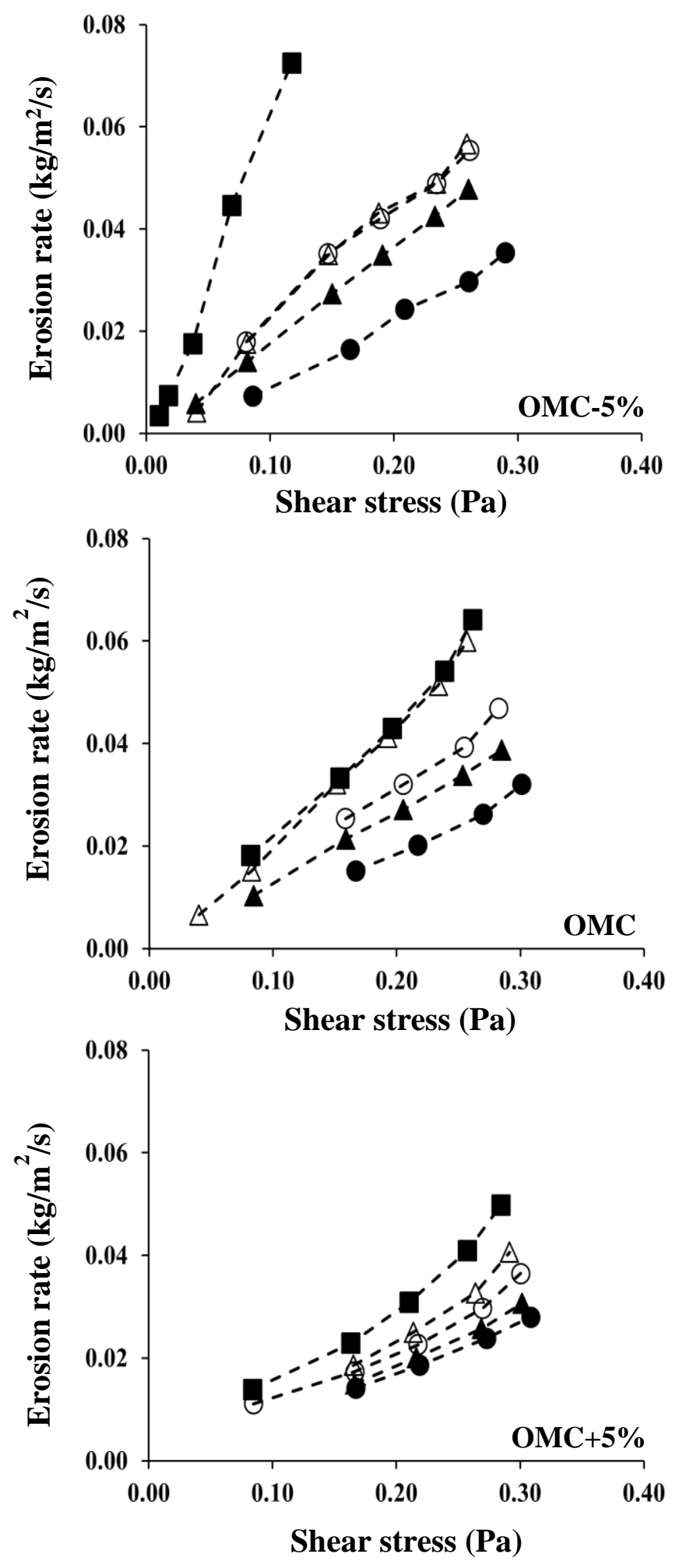

Fig. 6 Pin hole test results representing plots of erosion rate with shear stress 


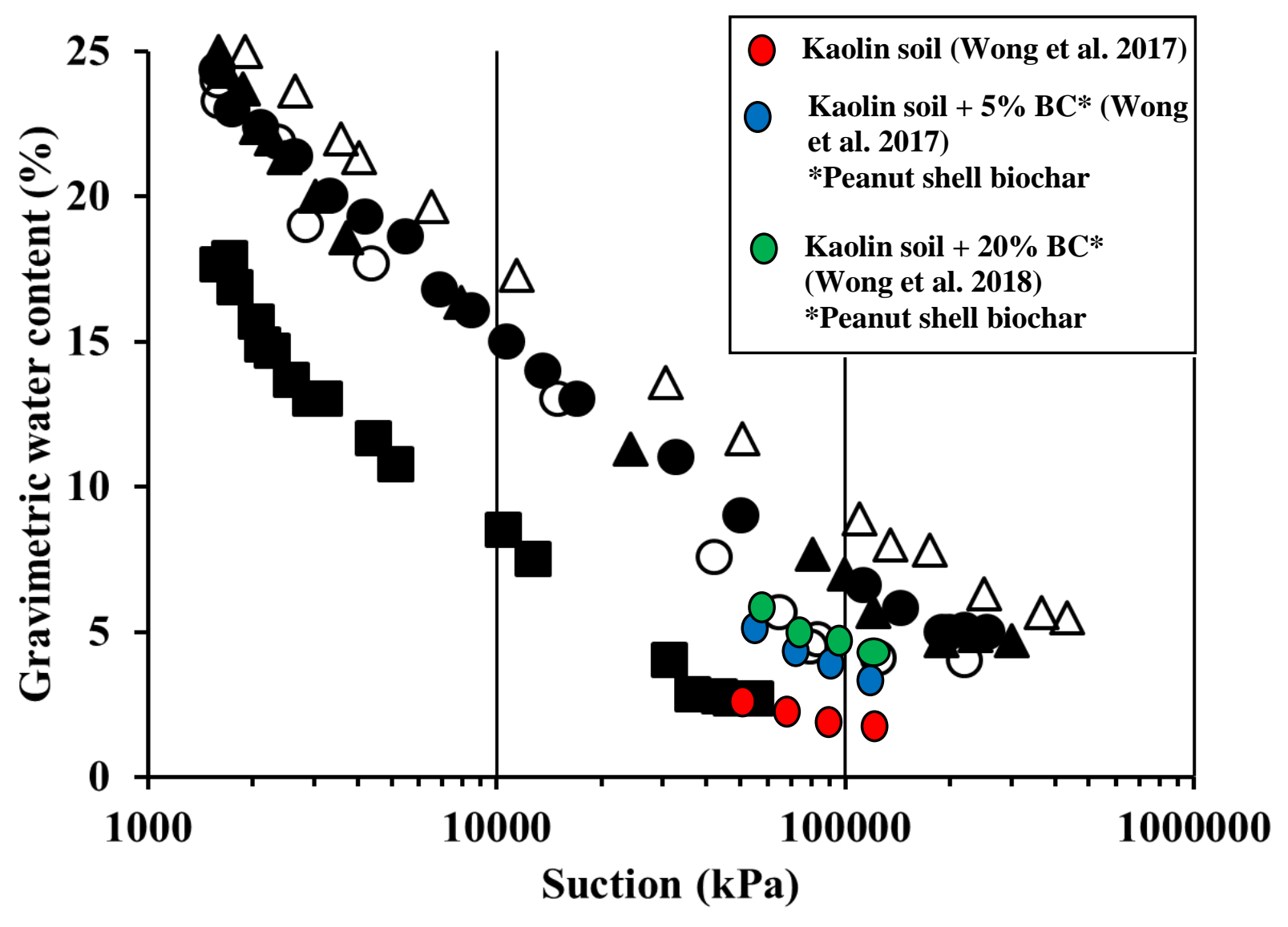

-7 Bare soil $\quad$ - CW-350-5\% $\quad-\mathrm{CW}-350-10 \% \quad$ A. CW-550-5\% $\quad-\Delta-\mathrm{CW}-550-10 \%$

Fig. 7 Soil water retention response for bare soil and biochar amended soil (at 5\% and 10\%) 
Table 1 Designation of materials used to study the geotechnical properties

\begin{tabular}{ccc}
\hline Test designation & Biochar percentage $(\%)$ & Pyrolysis temperature $\left({ }^{\circ} \mathrm{C}\right)$ \\
\hline BS & NA & NA \\
CW-350-5\% & 5 & 350 \\
CW-350-10\% & 10 & 350 \\
CW $-550-5 \%$ & 5 & 550 \\
CW $-550-10 \%$ & 10 & 550 \\
\hline
\end{tabular}


Table 2 Physical properties of cedar wood biochar pyrolyzed at $350{ }^{\circ} \mathrm{C}$ and $550{ }^{\circ} \mathrm{C}$

\begin{tabular}{|c|c|c|c|c|c|c|c|}
\hline \multirow{2}{*}{ Designation } & \multicolumn{4}{|c|}{ Consistency limits } & \multicolumn{2}{|c|}{ Compaction parameters } & \multirow{2}{*}{$\begin{array}{c}\text { Specific } \\
\text { gravity of } \\
\text { soil and } \\
\text { biochar }\end{array}$} \\
\hline & $\begin{array}{l}\text { Liquid limit } \\
\qquad \%)\end{array}$ & $\begin{array}{c}\text { Plastic limit } \\
(\%)\end{array}$ & $\begin{array}{l}\text { Plasticity } \\
\text { index }\end{array}$ & $\begin{array}{c}\text { Shrinkage } \\
\text { limit }(\%)\end{array}$ & $\begin{array}{c}\text { Optimum } \\
\text { Moisture } \\
\text { Content }(\%)\end{array}$ & $\begin{array}{l}\text { Maximum } \\
\text { Dry } \\
\text { Density } \\
\text { (g/cc) }\end{array}$ & \\
\hline & & STM D 4318-00 & & $\begin{array}{c}\text { ASTM D } \\
4943-18\end{array}$ & \multicolumn{2}{|c|}{ ASTM D 1557-15 } & $\begin{array}{c}\text { ASTM D } \\
854-14\end{array}$ \\
\hline $\mathrm{BS}$ & 43.6 & 25.5 & 18.1 & 13.9 & 17.2 & 1.70 & 2.74 \\
\hline CW-350-5\% & 50.4 & 30.4 & 20.1 & 12.7 & 19.1 & 1.55 & 1.11 \\
\hline CW-350-10\% & 54.4 & 33.4 & 21.0 & 16.4 & 25.2 & 1.31 & \\
\hline CW-550-5\% & 51.9 & 29.2 & 22.7 & 10.2 & 22.6 & 1.49 & 1.08 \\
\hline CW-550-10\% & 58.5 & 30.9 & 27.5 & 18.4 & 24.0 & 1.4 & \\
\hline
\end{tabular}


Table 3 Pyrolysis condition, chemical properties, and particle size of the produced biochar

\begin{tabular}{|c|c|c|}
\hline \multirow{2}{*}{$\begin{array}{l}\text { Feedstock } \\
\text { Pyrolysis temperature }\end{array}$} & \multicolumn{2}{|c|}{ Cedar wood } \\
\hline & $350^{\circ} \mathrm{C}$ & $550^{\circ} \mathrm{C}$ \\
\hline Pyrolysis process & Slow pyrolysis & Slow pyrolysis \\
\hline \multicolumn{3}{|l|}{ Elemental composition } \\
\hline Carbon $(\%)$ & 68.71 & 78.74 \\
\hline Nitrogen $(\%)$ & 0.41 & 0.58 \\
\hline \multicolumn{3}{|l|}{ Molar ratio } \\
\hline $\mathrm{C}: \mathrm{N}$ & $168: 1$ & $135: 1$ \\
\hline Ash content (\%) & 24.1 & 29.5 \\
\hline CEC (cmol kg-1) & 21.67 & 8.38 \\
\hline
\end{tabular}

